\title{
The role of the medial prefrontal cortex in trace fear extinction
}

\author{
Janine L. Kwapis, Timothy J. Jarome, and Fred J. Helmstetter \\ Department of Psychology, University of Wisconsin-Milwaukee, Milwaukee, Wisconsin 53211, USA
}

\begin{abstract}
The extinction of delay fear conditioning relies on a neural circuit that has received much attention and is relatively well defined. Whether this established circuit also supports the extinction of more complex associations, however, is unclear. Trace fear conditioning is a better model of complex relational learning, yet the circuit that supports extinction of this memory has received very little attention. Recent research has indicated that trace fear extinction requires a different neural circuit than delay extinction; trace extinction requires the participation of the retrosplenial cortex, but not the amygdala, as noted in a previous study. Here, we tested the roles of the prelimbic and infralimbic regions of the medial prefrontal cortex in trace and delay fear extinction by blocking NMDA receptors during extinction learning. We found that the prelimbic cortex is necessary for trace, but not for delay fear extinction, whereas the infralimbic cortex is involved in both types of extinction. These results are consistent with the idea that trace fear associations require plasticity in multiple cortical areas for successful extinction. Further, the infralimbic cortex appears to play a role in extinction regardless of whether the animal was initially trained in trace or delay conditioning. Together, our results provide new information about how the neural circuits supporting trace and delay fear extinction differ.
\end{abstract}

[Supplemental material is available for this article.]

Extinction is a behavioral paradigm in which responding to a conditioned stimulus is reduced following repeated presentation of the stimulus in the absence of reinforcement (Pavlov 1927). It is generally accepted that extinction reflects new learning, rather than unlearning of the initial contingency (Pavlov 1927; Rescorla and Heth 1975; Bouton and King 1983; Bouton and Nelson 1994; Berman and Dudai 2001; Myers and Davis 2002). Extinction has received extensive attention recently, as it has been likened to an animal model of exposure-based therapies used clinically to treat anxiety disorders (Davis 2002; Milad and Quirk 2012).

Our understanding of the neural circuit of extinction comes primarily from work studying the extinction of delay fear conditioning. In delay fear conditioning, an initially neutral conditional stimulus (CS), like a tone or white noise, is immediately followed by a naturally aversive unconditional stimulus (UCS), usually a shock. Importantly, delay fear can be acquired and expressed without contingency awareness in humans (Clark and Squire 1998; Knight et al. 2006) and is a model of simple, implicit fear memory. Extinction of delay fear requires plastic changes in a number of brain regions, including the amygdala (Falls et al. 1992; Parsons et al. 2010), and the infralimbic medial prefrontal cortex (IL mPFC) (Burgos-Robles et al. 2007; Sotres-Bayon et al. 2009; Parsons et al. 2010). Plasticity in the amygdala may reflect updating of the original memory for delay fear conditioning, which is thought to be stored in the amygdala (Maren et al. 1996a; Maren 2001; Gale et al. 2004; Serrano et al. 2008; Kwapis et al. 2009). Accordingly, manipulations of the amygdala can disrupt the consolidation (Bailey et al. 1999; Schafe and LeDoux 2000; Parsons et al. 2006; Jarome et al. 2011), storage (Gale et al. 2004; Serrano et al. 2008; Kwapis et al. 2009), and extinction ( $\mathrm{Lu}$ et al. 2001; Lin et al. 2003; Herry et al. 2006; Kim et al. 2007; Sotres-Bayon et al. 2007) of delay fear memory. Plasticity in the IL, on the other hand, appears to support the extinction memory itself, as manip-

\section{Corresponding author: fjh@uwm.edu}

Article is online at http://www.learnmem.org/cgi/doi/10.1101//m.036517.114. ulations of the IL disrupt extinction retention (Morgan et al. 1993; Quirk et al. 2000; Hugues et al. 2004; Burgos-Robles et al. 2007; Sotres-Bayon et al. 2007; Sierra-Mercado et al. 2011). Coordinated actions between the IL, the amygdala, and the hippocampus produce decreased responding to the CS in delay fear extinction (Myers and Davis 2007; Sierra-Mercado et al. 2011).

Although the neural circuit of delay fear extinction has been generally identified, far less is currently understood about the extinction of more complex fear memories. One model of complex fear learning is trace fear conditioning, in which the CS and UCS are separated by an empty period of time, called the trace interval. Trace fear conditioning involves a more complex CS-UCS relationship and learning requires the participation of the hippocampus (McEchron et al. 1998, 2000; Quinn et al. 2002) and prelimbic mPFC (PL) (Runyan et al. 2004; Gilmartin and McEchron 2005; Gilmartin and Helmstetter 2010; Gilmartin et al. 2012, 2013). Importantly, trace fear conditioning requires contingency awareness in humans for successful acquisition (Knight et al. 2006; Weike et al. 2007). This awareness requirement, along with hippocampal involvement and the complex and relational qualities of the task make trace fear conditioning a particularly good paradigm for modeling explicit fear memory in rodents (Squire 1992; Han et al. 2003; Kwapis et al. 2014).

Recent work has demonstrated that the extinction of trace fear requires a different neural circuit than that identified for delay fear extinction (Kwapis et al. 2014). Specifically, this study demonstrated that the amygdala was required for delay fear extinction, consistent with previous work (Falls et al. 1992; Lu et al. 2001; Lin et al. 2003; Herry et al. 2006; Kim et al. 2007; SotresBayon et al. 2007; Sierra-Mercado et al. 2011), but the amygdala

(C) 2014 Kwapis et al. This article is distributed exclusively by Cold Spring Harbor Laboratory Press for the first 12 months after the full-issue publication date (see http://learnmem.cshlp.org/site/misc/terms.xhtml). After 12 months, it is available under a Creative Commons License (Attribution-NonCommercial 4.0 International), as described at http://creativecommons.org/ licenses/by-nc/4.0/. 
was not involved in trace fear extinction (Kwapis et al. 2014). The retrosplenial cortex, on the other hand, was shown to play a role in trace, but not in delay fear extinction (Kwapis et al. 2014). The neural circuit required for extinction of complex trace fear associations, therefore, appears to differ from that supporting the extinction of basic delay fear. The extent to which the trace and delay extinction circuits differ is currently unclear.

Here, we aimed to further elucidate how the delay and trace fear extinction circuits differ by testing the role of the medial prefrontal cortex in both types of extinction. To this end, we used localized, restricted infusions of the NMDA glutamate receptor antagonist 2-amino-5-phosphonovaleric acid (APV) targeted to either the prelimbic or infralimbic region of the medial prefrontal cortex to test whether plasticity in each region is necessary for delay or trace extinction. NMDA receptors play a crucial role in triggering synaptic plasticity (Collingridge et al. 1983; Malenka and Nicoll 1999; Day et al. 2003) and are necessary for many forms of learning, including fear conditioning (Miserendino et al. 1990; Campeau et al. 1992; Fanselow and Kim 1994; Maren et al. 1996b; Gewirtz et al. 1997; Gilmartin and Helmstetter 2010). Importantly, extinction-related plasticity requires NMDA receptor activation; blocking NMDA receptors in either the amygdala (Falls et al. 1992; Lee and Kim 1998; Santini et al. 2001; Sotres-Bayon et al. 2007) or infralimbic cortex (Burgos-Robles et al. 2007; SotresBayon et al. 2009) generally disrupts retention of delay fear extinction. By locally restricting our infusions to either the prelimbic or infralimbic region of the medial prefrontal cortex, we aimed to dissociate the roles of each structure in trace and delay fear extinction.

\section{Results}

\section{Histology}

Only rats with injector tips terminating in the appropriate locations (PL or IL) were included in the analyses (Fig. 1A,B). Most of the cannulae placements were appropriately located in the target region. Five animals were excluded from analyses based on misplaced cannula (PL placements: $n=2$; IL placements, $n=3$ ). Cannulae placements for the remaining 86 animals were deemed acceptable.

\section{Experiment 1: blocking NMDA receptors in the prelimbic cortex impairs trace, but not delay fear extinction}

We first tested whether the PL is necessary for trace or delay fear extinction (Fig. 1C). As the PL plays a role in the acquisition (Runyan et al. 2004; Gilmartin and McEchron 2005; Gilmartin and Helmstetter 2010; Gilmartin et al. 2013) and possibly storage (Runyan and Dash 2004; Runyan et al. 2004; Blum et al. 2006) (but see Quinn et al. 2008) of trace fear conditioning, it was hypothesized that NMDA receptor-dependent plasticity in the PL would be required for trace, and not delay fear extinction. On day 1 , animals were trained with strength-matched delay or trace fear conditioning in Context A (Fig. 2A). All animals showed normal acquisition before drug infusion and no group differences were observed in the levels of post-shock freezing for either delay $\left(t_{(12)}=1.049\right.$, $P=0.315)$ or trace $\left(t_{(14)}=-0.594, P=0.562\right)$ animals.

On day 2, animals were given intra-PL infusions of the NMDA receptor inhibitor APV or vehicle (ACSF) 5 min before extinction training in Context B (Fig. 2B; Supplemental Fig. S1A). There was no effect of APV infusion on freezing levels during the first eight CS presentations of the extinction training session for either delay $\left(t_{(12)}=-1.230, P=0.242\right)$ or trace $\left(t_{(14)}=\right.$ $-0.787, P=0.445$ ) animals (Fig. $2 B$; see Supplemental Fig. S1A for full extinction timecourse). This suggests that NMDA receptor blockade in the PL does not disrupt freezing behavior during either delay or trace extinction.

The following day, animals were given a drug-free retention test in order to assess their memory for the extinction session they received in the presence of APV or vehicle (Fig. 2C). We found that APV infusion into the PL disrupted retention of trace fear extinction without affecting delay extinction memory. For delay animals, average freezing during an average of all eight CS trials revealed no significant difference between vehicle and APV animals $\left(t_{(12)}=-0.732, \quad P=0.478\right)$, indicating that the drug did not impair extinction memory. For trace animals, on the other hand, APV animals showed significantly higher freezing to the CS than vehicle controls $\left(t_{(14)}=-2.332, \quad P=\right.$ 0.035). Together, these findings suggest that NMDA receptors in the prelimbic cortex are necessary for trace fear extinction, but are not required for extinction of delay fear.

\section{Experiment 2: blocking NMDA receptors in the infralimbic cortex enhances both delay and trace fear extinction}

In our second experiment, we tested whether NMDA receptors in the infralimbic cortex are involved in delay or trace fear extinction (Fig. 1C). As the IL plays a documented role in extinction (Morgan et al. 1993; Quirk et al. 2000; Hugues et al. 2004; Burgos-Robles et al. 2007; Sotres-Bayon et al. 2007; Sierra-

Figure 1. $(A, B)$ Location of acceptable cannulae placements in either the prelimbic $(A)$ or infralimbic $(B)$ cortex. Animals were infused with either ACSF (white symbols) or APV (black symbols) before extinction of delay or trace conditioning. (C) The experimental timeline. 
A Training

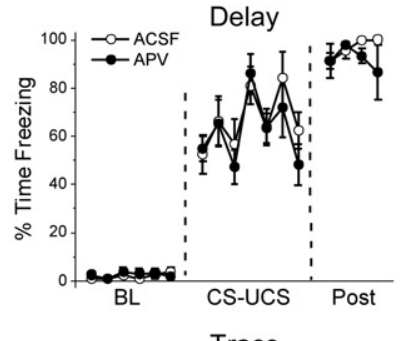

Trace

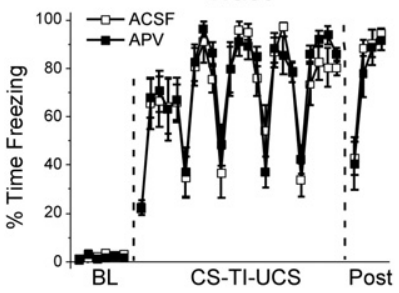

B Extinction

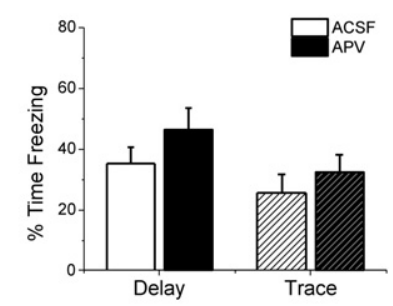

C Extinction Retention Test

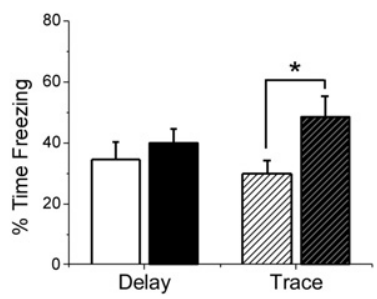

Figure 2. APV infusion into the prelimbic cortex before extinction disrupts extinction retention the following day for Trace, but not Delay animals. (A) Freezing during training for Delay (top) and Trace (bottom) animals. Data are shown as average percent time freezing per minute. $(B)$ Freezing during the first eight CS presentations of the extinction session. APV infusion before extinction did not impair freezing for either Delay or Trace animals. (C) Freezing during the extinction retention test on day 3. Trace animals given APV show impaired extinction retention relative to ACSF controls. APV did not affect extinction for Delay animals. $(*) P<0.05$.

Mercado et al. 2011), and previous research from our laboratory has shown that a key marker of plasticity (ERK phosphorylation) is increased in the IL following both delay and trace fear extinction (Kwapis et al. 2014), we predicted that the IL would be involved in the extinction of both types of memory.

Training occurred normally for both delay and trace animals in Experiment 2. No significant differences in freezing levels were observed during the training post-shock period for either delay $\left(t_{(27)}=-0.189, P=0.852\right)$ or trace $\left(t_{(25)}=-0.622, P=0.540\right)$ animals (Fig. 3A). This indicates that both groups learned fear conditioning normally before drug infusion.

The following day, animals were given intra-IL infusion of either APV or vehicle (ACSF) $\sim 5$ min before extinction training. During extinction, both delay and trace APV animals showed reduced freezing compared with vehicle controls (Fig. 3B; see Supplemental Fig. S1B for full timecourse). Delay animals given APV showed significantly lower freezing levels than vehicle animals during the first eight CS presentations $\left(t_{(27)}=6.831, P<\right.$ 0.001). Similarly, trace APV animals also showed significantly lower freezing than vehicle controls during the first eight CS presentations $\left(t_{(25)}=6.077, P<0.001\right)$.

On day 3 , animals were given a drug-free extinction retention test (Fig. 3C). Intra-IL infusion of APV enhanced extinction for both delay and trace animals. An average of all eight CS test trials revealed significantly reduced freezing in delay animals given APV relative to delay vehicle animals $\left(t_{(27)}=3.342, P=0.002\right)$. Similarly, trace animals given APV show significantly lower freezing during the CS compared with trace vehicle animals $\left(t_{(25)}=\right.$ $2.937, P=0.007)$. This suggests that inhibiting NMDA receptors in the IL enhances extinction for both delay and trace associations.

In this study, we used two types of cannulae placements to target the IL: straight cannulae inserted directly above the target region and cannulae angled toward the midline at $30^{\circ}$ to avoid damaging the PL region just dorsal to the IL. The data are broken down by cannulae type in Supplemental Figure S2. To ensure that both cannulae types appropriately targeted the IL region, we infused a fluorescent secondary antibody into the IL and visualized its spread. Infusions through both straight (Supplemental Fig. S2A) and angled (Supplemental Fig. S2D) cannulae appropriately targeted the IL region of the medial prefrontal cortex. APV infusion into both types of cannulae also produced the same general behavioral pattern (Supplemental Fig. S2B,C,E,F). Specifically, we observed significant decreases in freezing for both delay and trace animals during the extinction session for both straight (Supplemental Fig. S2B; Delay: $t_{(12)}=6.136, P<0.001$; Trace: $t_{(11)}=6.278, P<0.001$ ) and angled (Supplemental Fig. S2E; Delay: $t_{(13)}=3.915, P=0.002$; Trace: $\left.t_{(12)}=4.501, P=0.001\right)$ cannulae. During the extinction retention test, we observed decreased freezing in APV animals for both delay and trace animals for both types of cannulae. This effect was significant for both delay $\left(t_{(12)}=2.429, P=0.032\right)$ and trace $\left(t_{(11)}=3.191\right.$, $P=0.009$ ) animals infused through straight cannulae (Supplemental Fig. S2C). For angled cannulae (Supplemental Fig. S2F), delay animals showed significantly reduced freezing relative to ACSF controls $\left(t_{(13)}=3.320, P=0.006\right)$ while trace animals given APV show a nonsignificant decrease in freezing $\left(t_{(12)}=1.247, P=\right.$ 0.236). Trace ACSF animals in this group had low freezing levels at test, making it difficult to detect any enhanced extinction in the APV animals. Regardless, both types of cannulae produce similar behavior patterns, indicating that APV infusion into the IL enhanced extinction retention regardless of damage to the PL. Together, our results demonstrate that NMDA receptor blockade in the IL affects delay and trace extinction in the same manner: it impairs recall of both delay and trace associations and enhances extinction learning for both types of conditioning.

\section{Discussion}

The goal of this study was to identify the roles of the prelimbic and infralimbic subregions of the medial prefrontal cortex in delay
A Training
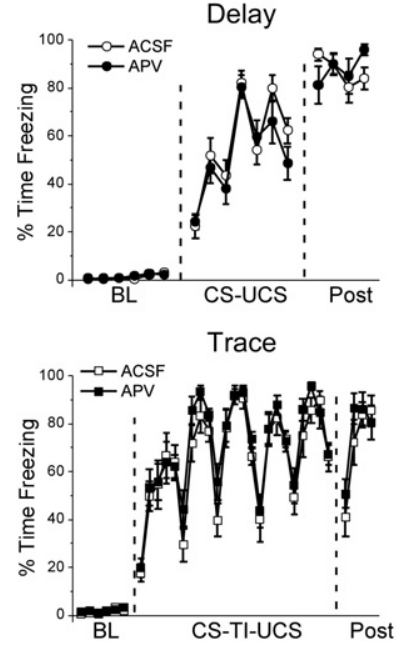

B Extinction
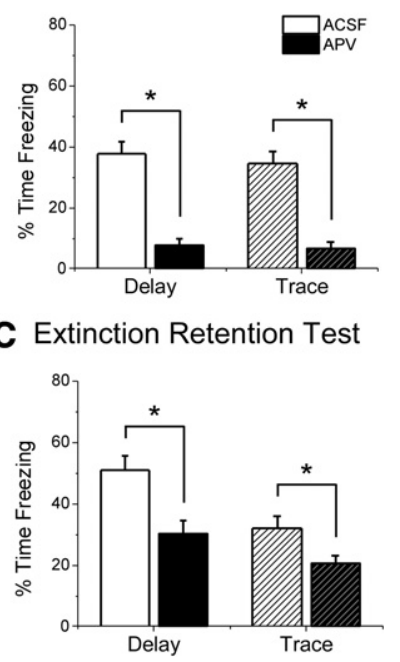

Figure 3. APV infusion into the infralimbic cortex impairs freezing during extinction and enhances extinction retention the following day for both Delay and Trace animals. (A) Freezing during training for Delay (top) and Trace (bottom) animals. Data are shown as average percent time freezing per minute. (B) Freezing during the first eight CS presentations of the extinction session. APV infusion before extinction impaired freezing for both Delay and Trace animals. (C) Freezing during the extinction retention test on day 3. Both Delay and Trace animals infused with APV show enhanced extinction retention relative to ACSF controls. $\left(^{*}\right) P<0.05$. 
and trace fear extinction in order to better understand how the extinction circuits of these two associations differ. We found that inhibiting NMDA receptors in the prelimbic cortex disrupted trace fear extinction without affecting delay extinction, whereas NMDA receptor blockade in the infralimbic cortex enhanced extinction for both delay and trace animals. Further, inhibiting NMDA receptors in the infralimbic cortex disrupted freezing during the extinction session, suggesting that the retrieval of both delay and trace associations requires NMDA receptor activation in the IL. Together, our findings suggest that the infralimbic cortex plays a similar role in the extinction of both delay and trace fear associations, whereas the prelimbic cortex is selectively involved in extinguishing trace associations.

Our first experiment tested the role of the prelimbic cortex in trace and delay fear extinction. The prelimbic portion of the medial prefrontal cortex is known to play a role in trace fear acquisition (Runyan et al. 2004; Gilmartin and McEchron 2005; Gilmartin and Helmstetter 2010; Gilmartin et al. 2013) and storage (Runyan and Dash 2004; Runyan et al. 2004; Blum et al. 2006) but is not necessary to acquire basic delay fear conditioning (Gilmartin and Helmstetter 2010). Here, we showed that NMDA receptors in the PL are also necessary for trace, but not delay fear extinction. This suggests that the prelimbic cortex plays a key role in extinguishing trace fear associations in addition to its involvement in trace acquisition and storage. The PL does not appear to play a role in extinguishing delay fear associations, however, as manipulating PL before delay extinction had no effect on delay extinction retention. Importantly, NMDA receptor blockade in the PL had no effect on freezing expression during the extinction session for either delay or trace animals (Fig. 2B). Previous studies have shown that inactivation of the PL with muscimol impairs freezing expression during delay fear extinction (Sierra-Mercado et al. 2011). Together, these results suggest that neural activity but not NMDA receptor-dependent plasticity in the PL is required for delay fear expression.

In our second experiment, we tested whether NMDA receptors in the infralimbic cortex are necessary for delay and trace extinction. The IL has been identified as a crucial structure in extinguishing delay fear (Morgan et al. 1993; Quirk et al. 2000; Hugues et al. 2004; Burgos-Robles et al. 2007; Sotres-Bayon et al. 2007; Sierra-Mercado et al. 2011). IL neurons are believed to project to the intercalated cell layer of the amygdala, where they activate a group of GABAergic interneurons that inhibit projection neurons in the central nucleus of the amygdala, effectively shutting down amygdala output to prevent freezing behavior (Paré and Smith 1993; Royer et al. 1999; Paré et al. 2004; SotresBayon and Quirk 2010). We observed that inhibiting NMDA receptors in the IL disrupted freezing during the extinction session for both delay and trace animals. Further, NMDA receptor blockade augmented extinction, as both delay and trace animals given APV during extinction showed lower freezing the following day compared with ACSF animals. Importantly, the IL appears to play a similar role in both types of extinction; both delay and trace animals showed reduced freezing during extinction training and during the extinction retention test. This suggests that the IL plays a key role in extinction regardless of the specific type of training used.

The enhanced extinction that we saw following NMDA receptor blockade in the IL was somewhat unexpected. We anticipated that this manipulation would similarly affect delay and trace animals, as we observed, but we predicted that inhibiting intra-IL NMDA receptors would "impair" extinction retention, rather than enhancing it. Although a number of previous studies have demonstrated that disrupting activity (Sierra-Mercado et al. 2006, 2011) or signaling cascades (Hugues et al. 2004; BurgosRobles et al. 2007; Sotres-Bayon et al. 2007; Mueller et al. 2008) in the IL impair extinction memory for delay fear conditioning, there are a number of notable exceptions that show either no effect (Akirav et al. 2006a; Sotres-Bayon et al. 2009) or enhanced extinction (Akirav et al. 2006b) with preextinction IL manipulations. One important note is that other studies that have inhibited NMDA receptors in the IL targeted the ventromedial portion of the medial prefrontal cortex with a single midline cannula, including placements in both infralimbic and prelimbic tissue (Burgos-Robles et al. 2007; Laurent and Westbrook 2008; SotresBayon et al. 2009). In the current study, we used a low infusion volume and dual cannulae in order to selectively target the drug to the IL region of the MPFC and dissociate it from the dorsal PL region. It is possible that our effect was due to the precise infusion procedure, as neurons in the IL and PL have opposing roles in freezing expression (Gilmartin and McEchron 2005; VidalGonzalez et al. 2006; Sierra-Mercado et al. 2011). This would suggest that while inactivation of NMDA receptors in both PL and IL regions impairs extinction memory, selectively inhibiting NMDA receptors in the infralimbic cortex enhances extinction retention. Alternatively, it is possible that procedural differences (such as our ABB design versus others' AAA design with context preexposure) or a difference in the specific NMDA receptor antagonist used (APV, used in the present study versus CPP or ifenprodil used in others' studies) may explain these discrepant results. Nonetheless, our results were consistent; two different types of cannulae placements produced the same general behavioral results (Supplemental Fig. S2) and demonstrated that both delay and trace fear extinction were enhanced with intra-IL blockade of NMDA receptors.

One might argue that our preextinction blockade of NMDA receptors in the IL may have impaired memory retrieval or reconsolidation, rather than enhancing extinction learning. Although intra-IL infusion of APV did block freezing expression, this cannot explain why we would observe reduced freezing during the test session (Fig. 3C). If our manipulation solely prevented the retrieval of the CS-UCS association, one would expect the original fear memory to be intact the following day, with the APV group showing higher, rather than lower freezing at test. Similarly, it is unlikely that we would see reduced freezing if our manipulation disrupted reconsolidation. Blocking NMDA receptors prevents memory destabilization (Ben Mamou et al. 2006), effectively blocking the initiation of reconsolidation (Johansen et al. 2011; Jarome and Helmstetter 2013). Therefore, if intra-IL APV primarily affected reconsolidation, higher freezing would be anticipated, as the original fear memory would persist. Thus, although it is unlikely that our effects are due to an impairment of either retrieval or reconsolidation, future studies should test whether postextinction NMDA receptor blockade in the IL similarly enhances extinction memory.

One challenge to our results is that our experimental design required different interstimulus intervals (ISIs) for the delay and trace conditioning groups. Specifically, animals trained with trace fear conditioning had a longer period between the onset of the auditory cue and the onset of the shock $(30 \mathrm{sec})$ compared with the delay group (10 sec). It is possible that the longer ISI (rather than the inclusion of a trace interval) altered the extinction circuit. Previous work on trace conditioning has shown that the trace interval, not the ISI, changes the neural circuit required for acquisition; the hippocampus is required for trace, but not delay eyeblink acquisition when the ISI is held constant (Beylin et al. 2001). Further, if contiguity is restored in trace fear conditioning, the hippocampus is no longer required (Bangasser et al. 2006). Regardless of whether the ISI or the trace interval is making trace fear acquisition more difficult, it is clear that the extinction circuit for this association recruits different circuitry than extinction of delay fear. 
Our results indicate that the PL portion of the medial prefrontal cortex is only necessary for trace extinction, whereas the IL plays a role in both delay and trace fear extinction. Along with the results of a previous study (Kwapis et al. 2014), this suggests that trace fear extinction requires a different circuit than delay. Delay fear requires both the amygdala (Falls et al. 1992; Herry et al. 2006; Sotres-Bayon et al. 2007; Parsons et al. 2010; SierraMercado et al. 2011) and infralimbic cortex (Vidal-Gonzalez et al. 2006; Burgos-Robles et al. 2007; Sotres-Bayon et al. 2007; Laurent and Westbrook 2008; Sierra-Mercado et al. 2011; Kwapis et al. 2014) for proper extinction. Trace extinction, on the other hand, does not require plasticity in the amygdala (Kwapis et al. 2014), but requires NMDA receptors in the retrosplenial cortex (Kwapis et al. 2014), and in the infralimbic and prelimbic cortices, as shown here. Although the reason for this circuitry shift is unclear, it is tempting to conclude that trace and delay fear memories are stored in different brain regions, causing different structures to be involved in their extinction (see Fig. 4). It is wellestablished that delay fear memory relies on the amygdala for storage (Maren et al. 1996a; Maren 2001; Gale et al. 2004; Serrano et al. 2008; Kwapis et al. 2009). The plastic changes that occur in the amygdala during delay extinction may reflect updating of those synaptic connections that support the delay engram, whereas IL plasticity appears to support the inhibitory connections that produce the extinction memory itself (Fig. 4A; Quirk and Mueller 2008). For trace fear, perhaps the memory is stored in distributed cortical circuits, rather than in the amygdala (Fig. 4B). There is evidence that the medial prefrontal cortex participates in encoding and storing the trace memory engram (Runyan and Dash 2004; Runyan et al. 2004; Blum et al. 2006). Plasticity in the amygdala

A Hypothesized Delay circuit

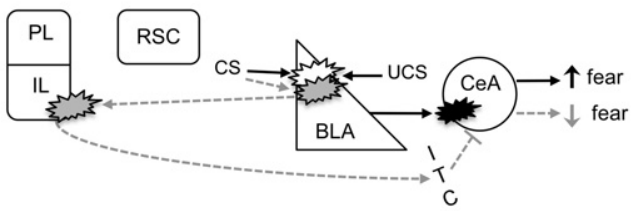

B Hypothesized Trace circuit

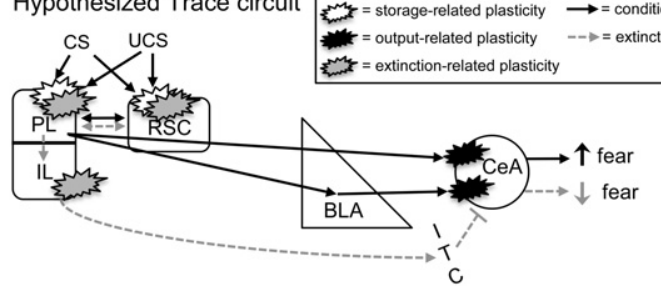

Figure 4. Hypothesized circuits for Delay $(A)$ and Trace $(B)$ fear conditioning and extinction. (A) Hypothesized Delay circuit. During conditioning (black arrows), CS and UCS information converges in the amygdala and promotes storage-related plasticity. Plasticity in the central nucleus of the amygdala (CeA) potentiates connections to "output" areas (hypothalamic and brainstem regions) that support the fear response. During extinction (gray dashed arrows), plasticity occurs in the BLA and IL. In the BLA, extinction-related plasticity is hypothesized to incorporate new information about the CS learned during extinction. In the IL, plasticity is hypothesized to support increased input to the ITC layer of the amygdala, which inhibits the CeA to "switch off" the fear response. ( $B)$ Proposed Trace circuit. Here, CS and UCS information converges in distributed cortical areas (including the prelimbic and retrosplenial cortices), which undergo plastic changes and ultimately store the association. Plasticity is also required in the amygdala, as connections to the CeA are potentiated to drive the fear response. Trace extinction would require plasticity in the cortical areas involved in storage, to allow for the new information about the CS to be incorporated into the existing association. Extinction would also produce plastic changes in the IL, as with delay, to drive inhibition of the amygdala. that occurs during training may reflect strengthening of the amygdala output circuit that facilitates connections to downstream structures to drive freezing, rather than storing the trace fear engram itself. If the prelimbic and retrosplenial cortices together store the trace association, rather than the amygdala, one would expect these structures, and not the amygdala, to undergo updating during extinction. Again, IL regions would participate in extinction to disable amygdala output, reducing the fear response. Although more work is necessary to test this hypothesized circuit, it could explain why the circuits for trace and delay extinction are different and why trace fear extinction requires cortical, rather than subcortical participation for extinction.

In conclusion, it appears that the trace and delay extinction circuits are distinct, with some common components. The prelimbic cortex appears to be uniquely necessary for trace fear extinction, whereas the infralimbic cortex plays a role in extinguishing both delay and trace fear. The extinction of complex trace associations, therefore, may require the participation of cortical structures that are not involved in delay fear extinction. Our understanding of the fear extinction circuit, which has been identified largely through studies of basic delay fear, may not be adequate to explain how more complex associations, like trace fear, are extinguished. This study suggests that additional cortical areas participate in extinguishing trace fear.

\section{Materials and Methods}

\section{Animals}

Subjects were 86 adult male Long-Evans rats obtained from Harlan (Madison, WI) weighing $\sim 350 \mathrm{~g}$. Rats were individually housed under a 14:10 h light-dark cycle (lights on at 7:00 a.m.) in a climate-controlled room. All experiments were conducted during the light portion of this cycle. Animals had free access to water and rat chow for the duration of the experiment. All procedures were approved by the university Animal Care and Use Committee and were in compliance with the National Institutes of Health guidelines.

\section{Surgery}

All animals were handled for $3 \mathrm{~d}$ prior to surgery. Immediately before surgery, rats were anesthetized with $2 \%-4 \%$ isoflurane in oxygen and implanted with bilateral stainless steel 26-gauge cannulae (Plastics One, Roanoke, VA) aimed at the prelimbic (PL) or infralimbic (IL) region of the medial prefrontal cortex. For the PL, guide cannulae were bilaterally implanted at a $15^{\circ}$ angle using stereotaxic coordinates (AP $+3.0 \mathrm{~mm}$; $\mathrm{ML} \pm 1.6 \mathrm{~mm}$; DV -3.0 $\mathrm{mm}$ ) relative to bregma (Paxinos and Watson 2007). For the IL, two sets of coordinates were used. Approximately half $(n=27)$ of the animals received dual guide cannulae implanted straight down to the PL/IL border using coordinates (AP +2.8; ML \pm 0.6 ; DV -4.4$)$ relative to bregma. The other half of the IL placements $(n=29)$ used cannulae that were implanted at a $30^{\circ}$ angle in order to minimize destruction of the PL tissue dorsal to the target site. Coordinates for the $30^{\circ}$ angled IL cannulae were: $\mathrm{AP}+2.8$; ML \pm 3.1 ; DV -4.2 relative to bregma. Cannulae were secured to the skull with stainless steel screws, superglue, and dental cement. Following surgery, the incision site was swabbed with a lidocaine/ prilocaine solution $(2.5 \% / 2.5 \%)$ to minimize discomfort during recovery. Stainless steel dummy cannulae were placed in the guide cannulae and were only removed during the drug infusion period. Each rat was allowed at least $7 \mathrm{~d}$ of post-operative recovery before the start of behavioral testing.

\section{Drug preparation and infusion}

Rats were transported and handled for $3 \mathrm{~d}$ before behavioral testing began. During each handling session, groups of four rats were transported to the laboratory, wrapped in a towel, and gently restrained by hand while the infusion pump was activated in order 
to allow the animals to habituate to its noise. Dummy cannulae were removed during this handling session and the surgical site was cleaned as needed with cotton swabs. Immediately after restraint handling, rats were returned to their homecages.

Drugs were prepared fresh on the day of infusion. The NMDA receptor antagonist D-APV (Tocris) was dissolved in ACSF to a final concentration of $10 \mu \mathrm{g} / \mu \mathrm{L}$. This dose was chosen based on its effectiveness in past studies in our laboratory (Gilmartin and Helmstetter 2010; Kwapis et al. 2014) and others (Falls et al. 1992; Maren et al. 1996b; Milton et al. 2008). In both the PL and IL, a volume of $0.3 \mu \mathrm{L} /$ side was infused at a rate of $0.5 \mu \mathrm{L} /$ min through 33-gauge injection cannulae that extended $0.5-$ $0.7 \mathrm{~mm}$ past the guide cannulae. Injectors remained in place for an additional $90 \mathrm{sec}$ after infusion to ensure proper diffusion.

\section{Apparatus}

Fear conditioning was conducted in a set of four identical chambers housed within sound-attenuating boxes (Context A). The floor was composed of stainless steel rods through which shocks were delivered. Each chamber was illuminated by an overhead 7.5-W bulb and was connected to its own shock generatorscrambler. Ventilation fans provided constant background noise $(\sim 60 \mathrm{~dB})$. Context A chambers were cleaned with a solution of $5 \%$ ammonium hydroxide between animals.

A second set of four identical chambers (Context B) was used to conduct extinction to the auditory CS. Context B contained a number of unique features, including infrared illumination, a solid and opaque textured floor panel, and a different cleaning solution with a distinct scent ( $5 \%$ acetic acid). All test sessions were conducted in Context B.

\section{Behavioral procedures}

\section{Training}

After adaptation to transportation and restraint handling, animals were trained with either delay or trace fear conditioning in Context A (Fig. 1C). We used strength-matched conditioning to produce approximately equivalent freezing levels for both types of training. The training parameters were chosen based on previous work from our laboratory (Kwapis et al. 2011, 2014), which has shown that four trials of delay fear conditioning with an ITI of $110 \pm 20 \mathrm{sec}$ produces approximately the same level of freezing as six trials of TFC with a longer ITI of $240 \pm 20 \mathrm{sec}$. For both delay and trace conditioning, the CS was a 10 -sec white noise cue $(72 \mathrm{~dB})$ and the UCS was a 1-sec foot shock $(1 \mathrm{~mA})$. For delay conditioning, the UCS was presented at the moment of the CS offset. For trace conditioning, the CS and UCS were separated by an empty 20 -sec trace interval. For both conditioning types, the first CS presentation occurred following a 6-min baseline period and the final shock was followed by a 4-min post-shock period.

\section{Extinction}

Twenty-four hours after training, animals were given a 40-trial extinction session in Context B (Fig. 1C). Approximately 5 min before the extinction training session, rats were given an infusion of APV or ACSF (vehicle) into the PL (Experiment 1) or IL (Experiment 2). Extinction training consisted of a 1-min baseline period followed by 40 presentations of the white noise CS (30 sec; $72 \mathrm{~dB} ; 60$-sec ITI). Immediately after the extinction session, animals were returned to their homecages.

\section{Extinction retention test}

On day 3, the rats were tested to assess how well they recalled the extinction session (Fig. 1C). Testing consisted of eight CS presentations (30 sec; $72 \mathrm{~dB}$; 60-sec ITI) presented after a 1-min baseline period in Context $\mathrm{B}$.

\section{Histology}

After behavioral testing was complete, all animals were killed with an overdose of isoflurane and transcardially perfused with saline followed by $10 \%$ buffered formalin. Heads were removed and submerged in buffered formalin for at least $24 \mathrm{~h}$ before the brains were removed and soaked in 30\% sucrose formalin for a minimum of 24 $h$. To verify cannulae placement, frozen $40-\mu \mathrm{m}$ sections were collected throughout the medial prefrontal cortex, mounted on slides, and stained with cresyl violet. Injection sites were determined using a rat brain atlas (Paxinos and Watson 2007) and animals with injection sites outside the appropriate structure were excluded from the analyses.

A subset of IL animals was injected with a fluorescent secondary antibody in order to better identify the region targeted by infusion and ensure that both types of IL cannulae (straight and angled) produced bilateral coverage of the IL region. For these animals, anti-mouse Alexa 488 (straight IL cannulae) or antirabbit Alexa 594 (angled IL cannulae) was injected into the IL at the same volume as the drug $(0.3 \mu \mathrm{L} /$ side $)$. Approximately $10 \mathrm{~min}$ after infusion, these animals were perfused as described above and brains were immediately removed and placed in sucrose formalin for 2-4 d in a dark container. The brains were sliced at $40 \mu \mathrm{m}$ in the dark, mounted on slides, and imaged with a fluorescent microscope (Nikon Eclipse) running NIS-Elements software. Alternate slices from each of these brains were mounted and stained with cresyl violet as described above.

\section{Data analysis}

The main dependent variable was the amount of time rats spent engaged in freezing behavior. Freezing was defined as the absence of all movement except for that required for respiration. The average percent time spent freezing was calculated using the FreezeScan 1.0 software (Clever Sys Inc.). The FreezeScan scoring parameters were chosen to closely match hand scoring methods used previously in our laboratory to measure freezing behavior (Parsons et al. 2010; Kwapis et al. 2014). Freezing was analyzed as a percentage of each minute during the acquisition session. The extinction and test sessions were hand scored by a trained observer who was blind to the treatment groups in order to correct for resting behavior. It was common for rats to lie down during the long extinction session and the subsequent test session. This resting behavior would be automatically scored as freezing by the computer, so it was necessary to manually hand score these sessions. For hand scoring, the behavior of each rat was scored as freezing or not freezing once every $5 \mathrm{sec}$ throughout the session. For both the extinction and test sessions, the average percent time spent freezing during the 30 -sec discrete CS presentations was calculated as a measure of fear to the CS. T-tests were used to identify drug effects for the average of the first eight trials of the extinction session or the average of all eight trials of the test session within each training type. In all analyses, an $\alpha$ value of 0.05 was required for significance.

\section{Acknowledgments}

This research was supported by the National Institutes of Mental Health (NIMH) grants R01MH069558 to F.J.H. and NIMH grant F31MH090685 to J.L.K. We thank Marieke R. Gilmartin and Jonathan L. Lee for technical assistance.

\section{References}

Akirav I, Khatsrinov V, Vouimba RM, Merhav M, Ferreira G, Rosenblum K, Maroun M. 2006a. Extinction of conditioned taste aversion depends on functional protein synthesis but not on NMDA receptor activation in the ventromedial prefrontal cortex. Learn Mem 13: 254-258.

Akirav I, Raizel H, Maroun M. 2006b. Enhancement of conditioned fear extinction by infusion of the GABA(A) agonist muscimol into the rat prefrontal cortex and amygdala. Eur J Neurosci 23: 758-764.

Bailey DJ, Kim JJ, Sun W, Thompson RF, Helmstetter FJ. 1999. Acquisition of fear conditioning in rats requires the synthesis of mRNA in the amygdala. Behav Neurosci 113: 276-282. 
Bangasser DA, Waxler DE, Santollo J, Shors TJ. 2006. Trace conditioning and the hippocampus: The importance of contiguity. J Neurosci 26: 8702-8706.

Ben Mamou C, Gamache K, Nader K. 2006. NMDA receptors are critical for unleashing consolidated auditory fear memories. Nat Neurosci 9: $1237-1239$.

Berman DE, Dudai Y. 2001. Memory extinction, learning anew, and learning the new: dissociations in the molecular machinery of learning in cortex. Science 291: 2417-2419.

Beylin AV, Gandhi CC, Wood GE, Talk AC, Matzel LD, Shors TJ. 2001. The role of the hippocampus in trace conditioning: temporal discontinuity or task difficulty? Neurobiol Learn Mem 76: 447-461.

Blum S, Hebert AE, Dash PK. 2006. A role for the prefrontal cortex in recall of recent and remote memories. Neuroreport 17: $341-344$.

Bouton ME, King DA. 1983. Contextual control of the extinction of conditioned fear: tests for the associative value of the context. J Exp Psychol Anim Behav Process 9: 248-265.

Bouton ME, Nelson JB. 1994. Context-specificity of target versus feature inhibition in a feature-negative discrimination. J Exp Psychol Anim Behav Process 20: 51-65.

Burgos-Robles A, Vidal-Gonzalez I, Santini E, Quirk GJ. 2007. Consolidation of fear extinction requires NMDA receptordependent bursting in the ventromedial prefrontal cortex. Neuron 53: $871-880$.

Campeau S, Miserendino MJ, Davis M. 1992. Intra-amygdala infusion of the $N$-methyl-D-aspartate receptor antagonist AP5 blocks acquisition but not expression of fear-potentiated startle to an auditory conditioned stimulus. Behav Neurosci 106: 569-574.

Clark RE, Squire LR. 1998. Classical conditioning and brain systems: the role of awareness. Science 280: 77-81.

Collingridge GL, Kehl SJ, McLennan H. 1983. The antagonism of amino acid-induced excitations of rat hippocampal CA1 neurones in vitro. J Physiol 334: 19-31.

Davis M. 2002. Role of NMDA receptors and MAP kinase in the amygdala in extinction of fear: clinical implications for exposure therapy. Eur J Neurosci 16: 395-398.

Day M, Langston R, Morris RG. 2003. Glutamate-receptor-mediated encoding and retrieval of paired-associate learning. Nature 424: 205-209.

Falls WA, Miserendino MJD, Davis M. 1992. Extinction of fear-potentiated Startle: blockade by infusion of an NMDA antagonist into the amygdala. J Neurosci 12: 854-863.

Fanselow MS, Kim JJ. 1994. Acquisition of contextual Pavlovian fear conditioning is blocked by application of an NMDA receptor antagonist D,L-2-amino-5-phosphonovaleric acid to the basolateral amygdala. Behav Neurosci 108: 210-212.

Gale GD, Anagnostaras SG, Godsil BP, Mitchell S, Nozawa T, Sage JR, Wiltgen B, Fanselow MS. 2004. Role of the basolateral amygdala in the storage of fear memories across the adult lifetime of rats. J Neurosci 24: $3810-3815$

Gewirtz JC, Falls WA, Davis M. 1997. Normal conditioned inhibition and extinction of freezing and fear-potentiated startle following electrolytic lesions of medical prefrontal cortex in rats. Behav Neurosci 111: $712-726$.

Gilmartin MR, Helmstetter FJ. 2010. Trace and contextual fear conditioning require neural activity and NMDA receptor-dependent transmission in the medial prefrontal cortex. Learn Mem 17: 289-296.

Gilmartin MR, McEchron MD. 2005. Single neurons in the medial prefrontal cortex of the rat exhibit tonic and phasic coding during trace fear conditioning. Behav Neurosci 119: 1496-1510.

Gilmartin MR, Kwapis JL, Helmstetter FJ. 2012. Trace and contextual fear conditioning are impaired following unilateral microinjection of muscimol in the ventral hippocampus or amygdala, but not the medial prefrontal cortex. Neurobiol Learn Mem 97: 452-464.

Gilmartin MR, Miyawaki H, Helmstetter FJ, Diba K. 2013. Prefrontal activity links nonoverlapping events in memory. J Neurosci 33: 10910-10914

Han CJ, O'Tuathaigh CM, van Trigt L, Quinn JJ, Fanselow MS, Mongeau R, Koch C, Anderson DJ. 2003. Trace but not delay fear conditioning requires attention and the anterior cingulate cortex. Proc Natl Acad Sci 100: $13087-13092$.

Herry C, Trifilieff P, Micheau J, Lüthi A, Mons N. 2006. Extinction of auditory fear conditioning requires MAPK/ERK activation in the basolateral amygdala. Eur J Neurosci 24: 261-269.

Hugues S, Deschaux O, Garcia R. 2004. Postextinction infusion of a mitogen-activated protein kinase inhibitor into the medial prefrontal cortex impairs memory of the extinction of conditioned fear. Learn Mem 11: 540-543.

Jarome TJ, Helmstetter FJ. 2013. The ubiquitin-proteasome system as a critical regulator of synaptic plasticity and long-term memory formation. Neurobiol Learn Mem 105: 107-116.
Jarome TJ, Werner CT, Kwapis JL, Helmstetter FJ. 2011. Activity dependent protein degradation is critical for the formation and stability of fear memory in the amygdala. PLoS One 6: e24349.

Johansen JP, Cain CK, Ostroff LE, LeDoux JE. 2011. Molecular mechanisms of fear learning and memory. Cell 147: 509-524.

Kim J, Lee S, Park H, Song B, Hong I, Geum D, Shin K, Choi S. 2007. Blockade of amygdala metabotropic glutamate receptor subtype 1 impairs fear extinction. Biochem Biophys Res Commun 355: 188-193.

Knight DC, Nguyen HT, Bandettini PA. 2006. The role of awareness in delay and trace fear conditioning in humans. Cogn Affect Behav Neurosci 6: $157-162$.

Kwapis JL, Jarome TJ, Lonergan ME, Helmstetter FJ. 2009. Protein kinase Mzeta maintains fear memory in the amygdala but not in the hippocampus. Behav Neurosci 123: 844-850.

Kwapis JL, Jarome TJ, Schiff JC, Helmstetter FJ. 2011. Memory consolidation in both trace and delay fear conditioning is disrupted by intra-amygdala infusion of the protein synthesis inhibitor anisomycin. Learn Mem 18: 728-732.

Kwapis JL, Jarome TJ, Lee JL, Gilmartin MR, Helmstetter FJ. 2014 Extinguishing trace fear engages the retrosplenial cortex rather than the amygdala. Neurobiol Learn Mem 113: 41-54.

Laurent V, Westbrook RF. 2008. Distinct contributions of the basolateral amygdala and the medial prefrontal cortex to learning and relearning extinction of context conditioned fear. Learn Mem 15: 657-666.

Lee H, Kim JJ. 1998. Amygdalar NMDA receptors are critical for new fear learning in previously fear-conditioned rats. J Neurosci 18: 8444-8454.

Lin CH, Yeh SH, Lu HY, Gean PW. 2003. The similarities and diversities of signal pathways leading to consolidation of conditioning and consolidation of extinction of fear memory. J Neurosci 23: 8310-8317.

Lu KT, Walker DL, Davis M. 2001. Mitogen-activated protein kinase cascade in the basolateral nucleus of amygdala is involved in extinction of fear-potentiated startle. J Neurosci 21: RC162.

Malenka RC, Nicoll RA. 1999. Long-term potentiation-a decade of progress? Science 285: 1870-1874.

Maren S. 2001. Is there savings for Pavlovian fear conditioning after neurotoxic basolateral amygdala lesions in rats? Neurobiol Learn Mem 76: $268-283$.

Maren S, Aharonov G, Fanselow MS. 1996a. Retrograde abolition of conditional fear after excitotoxic lesions in the basolateral amygdala of rats: absence of a temporal gradient. Behav Neurosci 110: 718-726.

Maren S, Aharonov G, Stote DL, Fanselow MS. 1996b. N-methyl-Daspartate receptors in the basolateral amygdala are required for both acquisition and expression of conditional fear in rats. Behav Neurosci 110: $1365-1374$

McEchron MD, Bouwmeester H, Tseng W, Weiss C, Disterhoft JF. 1998. Hippocampectomy disrupts auditory trace fear conditioning and contextual fear conditioning in the rat. Hippocampus 8: 638-646.

McEchron MD, Tseng W, Disterhoft JF. 2000. Neurotoxic lesions of the dorsal hippocampus disrupt auditory-cued trace heart rate (fear) conditioning in rabbits. Hippocampus 10: 739-751.

Milad MR, Quirk GJ. 2012. Fear extinction as a model for translational neuroscience: ten years of progress. Аnпu Rev Psychol 63: 129-151.

Milton AL, Lee JL, Butler VJ, Gardner R, Everitt BJ. 2008. Intra-amygdala and systemic antagonism of NMDA receptors prevents the reconsolidation of drug-associated memory and impairs subsequently both novel and previously acquired drug-seeking behaviors. J Neurosci 28: $8230-8237$.

Miserendino M, Sananes C, Melia K, Davis M. 1990. Blocking of acquisition but not expression of conditioned fear-potentiated startle by NMDA antagonists in the amygdala. Nature 345: 716-724.

Morgan MA, Romanski LM, LeDoux JE. 1993. Extinction of emotional learning: contribution of medial prefrontal cortex. Neurosci Lett 163: $109-113$

Mueller D, Porter JT, Quirk GJ. 2008. Noradrenergic signaling in infralimbic cortex increases cell excitability and strengthens memory for fear extinction. J Neurosci 28: 369-375.

Myers KM, Davis M. 2002. Behavioral and neural analysis of extinction. Neuron 36: $567-584$.

Myers KM, Davis M. 2007. Mechanisms of fear extinction. Mol Psychiatry 12: $120-150$.

Paré D, Smith Y. 1993. The intercalated cell masses project to the central and medial nuclei of the amygdala in cats. Neuroscience 57: 1077-1090.

Paré D, Quirk GJ, Ledoux JE. 2004. New vistas on amygdala networks in conditioned fear. J Neurophysiol 92: 1-9.

Parsons RG, Gafford GM, Helmstetter FJ. 2006. Translational control via the mammalian target of rapamycin pathway is critical for the formation and stability of long-term fear memory in amygdala neurons. J Neurosci 26: 12977-12983.

Parsons RG, Gafford GM, Helmstetter FJ. 2010. Regulation of extinction-related plasticity by opioid receptors in the ventrolateral periaqueductal gray matter. Front Behav Neurosci 4: 44. 
Pavlov IP. 1927. Conditioned reflexes: an investigation of the physiological activity of the cerebral cortex. Oxford University Press, London.

Paxinos G, Watson C. 2007. The rat brain in stereotaxic coordinates. Academic Press, San Diego, CA.

Quinn JJ, Oommen SS, Morrison GE, Fanselow MS. 2002. Post-training excitotoxic lesions of the dorsal hippocampus attenuate forward trace, backward trace, and delay fear conditioning in a temporally specific manner. Hippocampus 12: 495-504.

Quinn JJ, Ma QD, Tinsley MR, Koch C, Fanselow MS. 2008. Inverse temporal contributions of the dorsal hippocampus and medial prefrontal cortex to the expression of long-term fear memories. Learn Mem 15: 368-372.

Quirk GJ, Mueller D. 2008. Neural mechanisms of extinction learning and retrieval. Neuropsychopharmacology 33: 56-72.

Quirk GJ, Russo GK, Barron JL, Lebron K. 2000. The role of ventromedial prefrontal cortex in the recovery of extinguished fear. J Neurosci 20: $6225-6231$.

Rescorla RA, Heth CD. 1975. Reinstatement of fear to an extinguished conditioned stimulus. J Exp Psychol Anim Behav Process 1: 88-96.

Royer S, Martina M, Paré D. 1999. An inhibitory interface gates impulse traffic between the input and output stations of the amygdala. $J$ Neurosci 19: 10575-10583.

Runyan JD, Dash PK. 2004. Intra-medial prefrontal administration of SCH-23390 attenuates ERK phosphorylation and long-term memory for trace fear conditioning in rats. Neurobiol Learn Mem 82: 65-70.

Runyan JD, Moore AN, Dash PK. 2004. A role for prefrontal cortex in memory storage for trace fear conditioning. J Neurosci 24: 1288-1295.

Santini E, Muller RU, Quirk GJ. 2001. Consolidation of extinction learning involves transfer from NMDA-independent to NMDA-dependent memory. J Neurosci 21: 9009-9017.

Schafe GE, LeDoux JE. 2000. Memory consolidation of auditory Pavlovian fear conditioning requires protein synthesis and protein kinase $\mathrm{A}$ in the amygdala. J Neurosci 20: RC96.
Serrano P, Friedman EL, Kenney J, Taubenfeld SM, Zimmerman JM, Hanna J, Alberini C, Kelley AE, Maren S, Rudy JW, et al. 2008. PKMzeta maintains spatial, instrumental, and classically conditioned long-term memories. PLoS Biol 6: 2698-2706.

Sierra-Mercado D Jr, Corcoran KA, Lebron-Milad K, Quirk GJ. 2006. Inactivation of the ventromedial prefrontal cortex reduces expression of conditioned fear and impairs subsequent recall of extinction. Eur J Neurosci 24: 1751-1758.

Sierra-Mercado D, Padilla-Coreano N, Quirk GJ. 2011. Dissociable roles of prelimbic and infralimbic cortices, ventral hippocampus, and basolateral amygdala in the expression and extinction of conditioned fear. Neuropsychopharmacology 36: 529-538.

Sotres-Bayon F, Quirk GJ. 2010. Prefrontal control of fear: more than just extinction. Curr Opin Neurobiol 20: 231-235.

Sotres-Bayon F, Bush DE, LeDoux JE. 2007. Acquisition of fear extinction requires activation of NR2B-containing NMDA receptors in the lateral amygdala. Neuropsychopharmacology 32: 1929-1940.

Sotres-Bayon F, Diaz-Mataix L, Bush DE, LeDoux JE. 2009. Dissociable roles for the ventromedial prefrontal cortex and amygdala in fear extinction: NR2B contribution. Cereb Cortex 19: 474-482.

Squire LR. 1992. Memory and the hippocampus: a synthesis from findings with rats, monkeys, and humans. Psychol Rev 99: $195-231$.

Vidal-Gonzalez I, Vidal-Gonzalez B, Rauch SL, Quirk GJ. 2006. Microstimulation reveals opposing influences of prelimbic and infralimbic cortex on the expression of conditioned fear. Learn Mem 13: $728-733$.

Weike AI, Schupp HT, Hamm AO. 2007. Fear acquisition requires awareness in trace but not delay conditioning. Psychophysiology 44: $170-180$.

Received July 18, 2014; accepted in revised form October 5, 2014. 


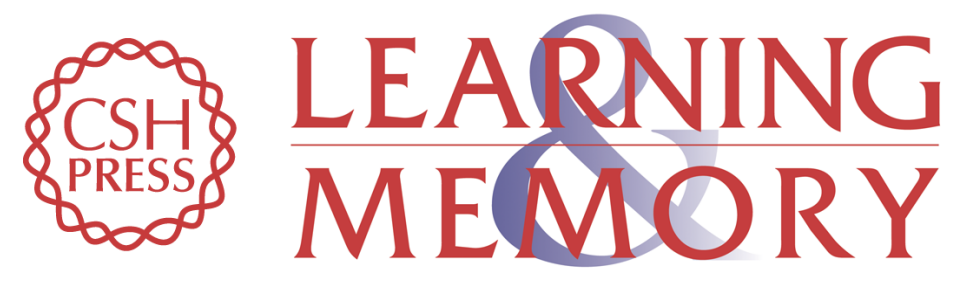

\section{The role of the medial prefrontal cortex in trace fear extinction}

Janine L. Kwapis, Timothy J. Jarome and Fred J. Helmstetter

Learn. Mem. 2015, 22:

Access the most recent version at doi:10.1101//m.036517.114

Supplemental
Material http://learnmem.cshlp.org/content/suppl/2014/12/05/22.1.39.DC1

References This article cites 75 articles, 26 of which can be accessed free at: http://learnmem.cshlp.org/content/22/1/39.full.html\#ref-list-1

Creative This article is distributed exclusively by Cold Spring Harbor Laboratory Press for the Commons License first 12 months after the full-issue publication date (see http://learnmem.cshlp.org/site/misc/terms.xhtml). After 12 months, it is available under a Creative Commons License (Attribution-NonCommercial 4.0 International), as described at http://creativecommons.org/licenses/by-nc/4.0/.

Email Alerting Receive free email alerts when new articles cite this article - sign up in the box at the Service top right corner of the article or click here. 